\title{
Hot Times in Tectonophysics: Mantle Plume Dynamics and Magmatic Perturbances
}

\author{
Vrishin R. Soman (Correspondence) \\ Department of Mechanical and Aerospace Engineering, Tandon School of Engineering, \\ New York University (NYU) \\ 6 MetroTech Center, Brooklyn, New York 11201, United States \\ E-mail: vrs283@nyu.edu
}

Received: March 9, 2020

Accepted: July 15, 2020

Published: July 28, 2020

doi:10.5296/jee.v11i2.16475

URL: https://doi.org/10.5296/jee.v11i2.16475

\begin{abstract}
Earth's dynamic lithospheric (plate) motions often are not obvious when considered in relation to the temporal stability of the crust. Seismic radiology experiments confirm that the extreme pressures and temperatures in the mantle, and to a lesser extent the asthenosphere, result in a heterogeneously viscous rheology. Occasionally, magmatic fluid makes its way through the lithospheric plate to the surface, appearing typically as a volcano, fissure eruption, or lava flow. When occurring away from the edges of plate boundaries, these long-lasting suppliers of lava, present over millions of years, are called mantle plumes, or 'hotspots.' Conventional definitions of mantle plumes note that they are stationary with respect to each other and the motion of the plates, passively tracing historical plate motion in volcanic formations such as the Hawaiian-Emperor island arc - the Plate Model. In this model, mantle plumes primarily occur as a consequence of lithospheric extension.

Recent empirical studies, however, have demonstrated that hotspots are not as geographically consistent as previously thought. They may move in relation to each other, as well as contribute actively toward lithospheric plate motions - the Plume Model. There is a lively, ongoing debate between the Plate and Plume hypotheses, essentially seeking to determine if mantle flow is merely a passive reaction to lithospheric plate motion (Plate Model), or whether plume activity in part drives this motion (Plume Model). More likely, it is a combination of passive and active mantle plume components that better describe the comprehensive behavior of these important and distinctive landscape forming features.
\end{abstract}

Keywords: Geodynamics, Hotspots, Mantle convection, Mantle plumes, Tectonophysics 


\section{Mantle Plume Rheology}

Introductory students first learning about tectonic plate activity and the Earth's interior are often reminded of the dynamically stable, yet always restructuring, constructive and deconstructive processes of the planet. Amidst the volcano-forming motion of the lithospheric plates, an oft utilized reference frame is anchored by the locations of mantle plumes, or 'hotspots', where semi-fluid lava appears on the surface of the lithosphere near the center of tectonic plates, forming subaqueous or subaerial volcanoes or vents e.g. Figure 1. The plumes originate in the deep mantle and rise via internal magmatic convection as a narrow stream, cooling and expanding as it wells up through the asthenosphere (Cronin \& Tasa, 2018). Because temperature and pressure decrease with elevation, the plume expands and cools into a larger and more viscous mass as it rises. The mantle plume head can be 1000 $\mathrm{km}$ in diameter, rising upwards by nearly two meters per year, exerting tremendous pressure on the base of the plate (Griffiths \& Campbell, 1990). These solidifying domes of rising magma, also known as diapirs, are considered to be central drivers of lithospheric plate extension (Morgan, 1972; Wilson, 1973).

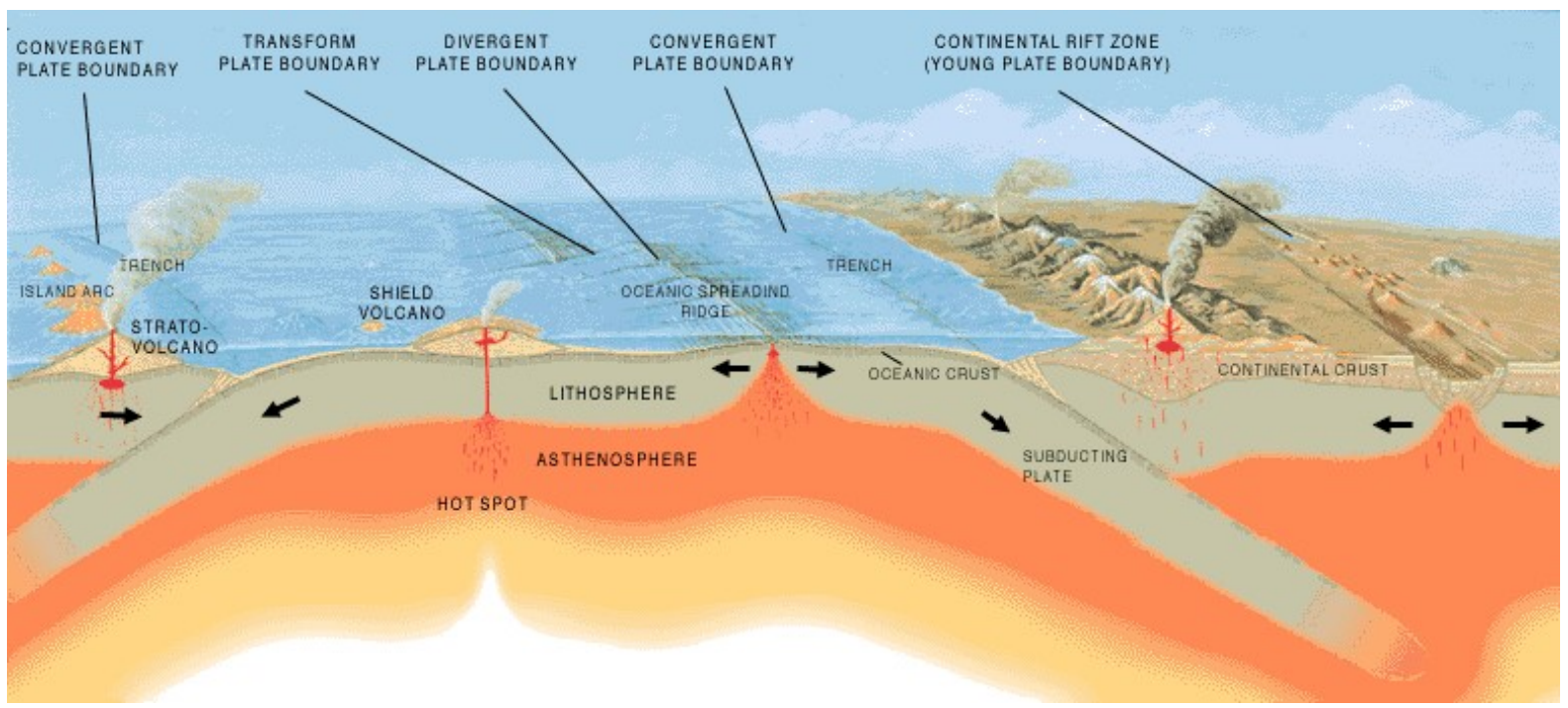

Figure 1. Typical plate tectonic boundaries and illustration of mantle fed volcanism

Ocean-ocean subduction (left) and ocean-continent subduction (right) cause differing volcanic expressions. Volcanism fueled by hotspot activity is shown (center). (sourced from the United States Geological Survey: http://pubs.usgs.gov/gip/dynamic/Vigil.html)

Hotspots away from plate boundaries are expressed on the surface as discontinuous, relatively aseismic seamounts or volcanic islands such as the Hawaiian Islands e.g. Figure 2. Traditionally, hotspots are viewed as stable and stationary features of the mantle. This assumption is generally why "a hotspot... can be used to define an external reference frame" from which plate motion is analyzed (Cronin \& Tasa, 2018). However, the energy-laden motions of the surface plates are not the only dynamic entity of the upper mantle and 


\section{Macrothink

asthenosphere to be accounted for - the mantle is also constantly in motion due to convection currents, governed by fluid mechanical principles.
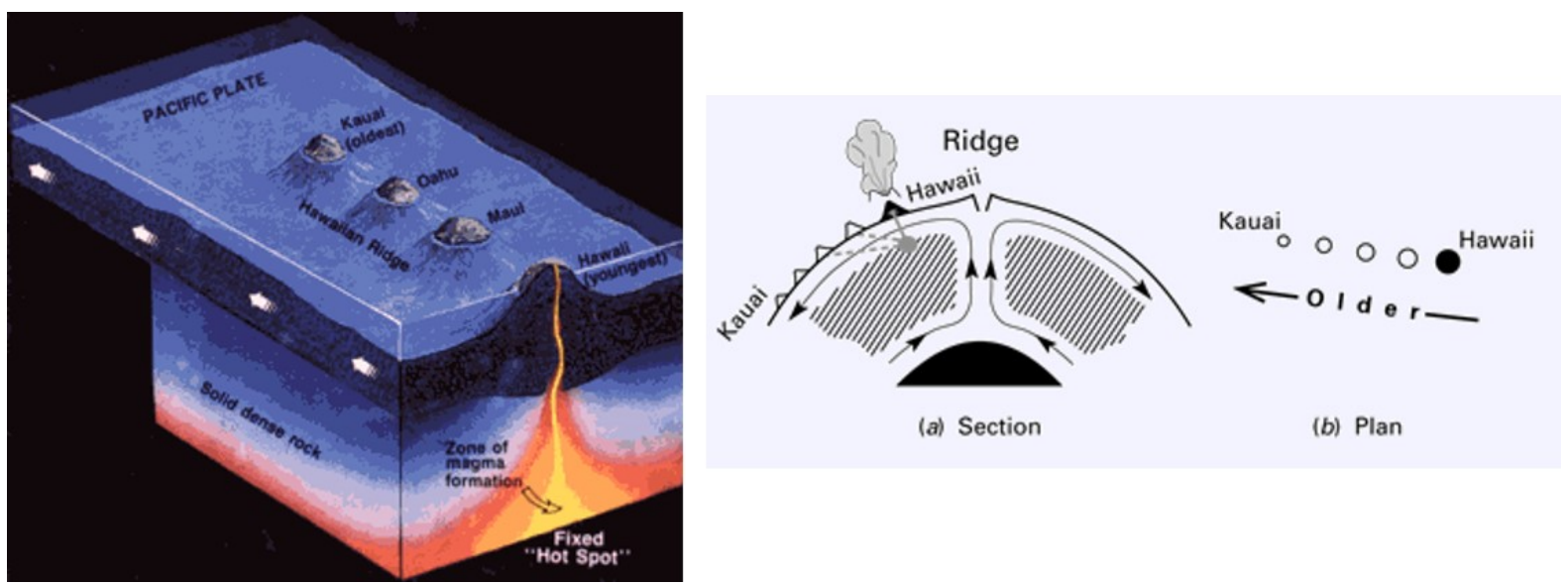

Figure 2. Artist's conception of the movement of the Pacific Plate over the fixed Hawaiian 'Hot Spot,' illustrating the formation of the Hawaiian Ridge-Emperor Seamount Chain (left). (Modified from a drawing provided by Maurice Krafft, Centre de Volcanologie, France). J. Tuzo Wilson's original diagram (slightly modified), published in 1963, to show his proposed origin of the Hawaiian Islands (right). (sourced from the United States Geological Survey: https://pubs.usgs.gov/gip/dynamic/hotspots.html)

Reconstructive studies have failed to generate models similar to what is seen in the Hawaiian-Emperor chain by consideration of plate motion alone, and global plate analyses do not account for abrupt change in orientation of these islands (Koppers, 2012). Further, paleomagnetic and radiometric age data "[indicate] that the Emperor Seamount trend was primarily formed by the rapid motion... of the Hawaiian hotspot plume during the Late Cretaceous and early-Tertiary times" (Koppers, 2012, italics added for emphasis). Contrary to conventional theories of stationary mantle plumes, plume motion may actually be the primary driver of plate activity, actively creating surface features such as the Hawaiian island arc e.g. Figure 3 (Bono \& Tarduno, 2019). 


\section{Macrothink}

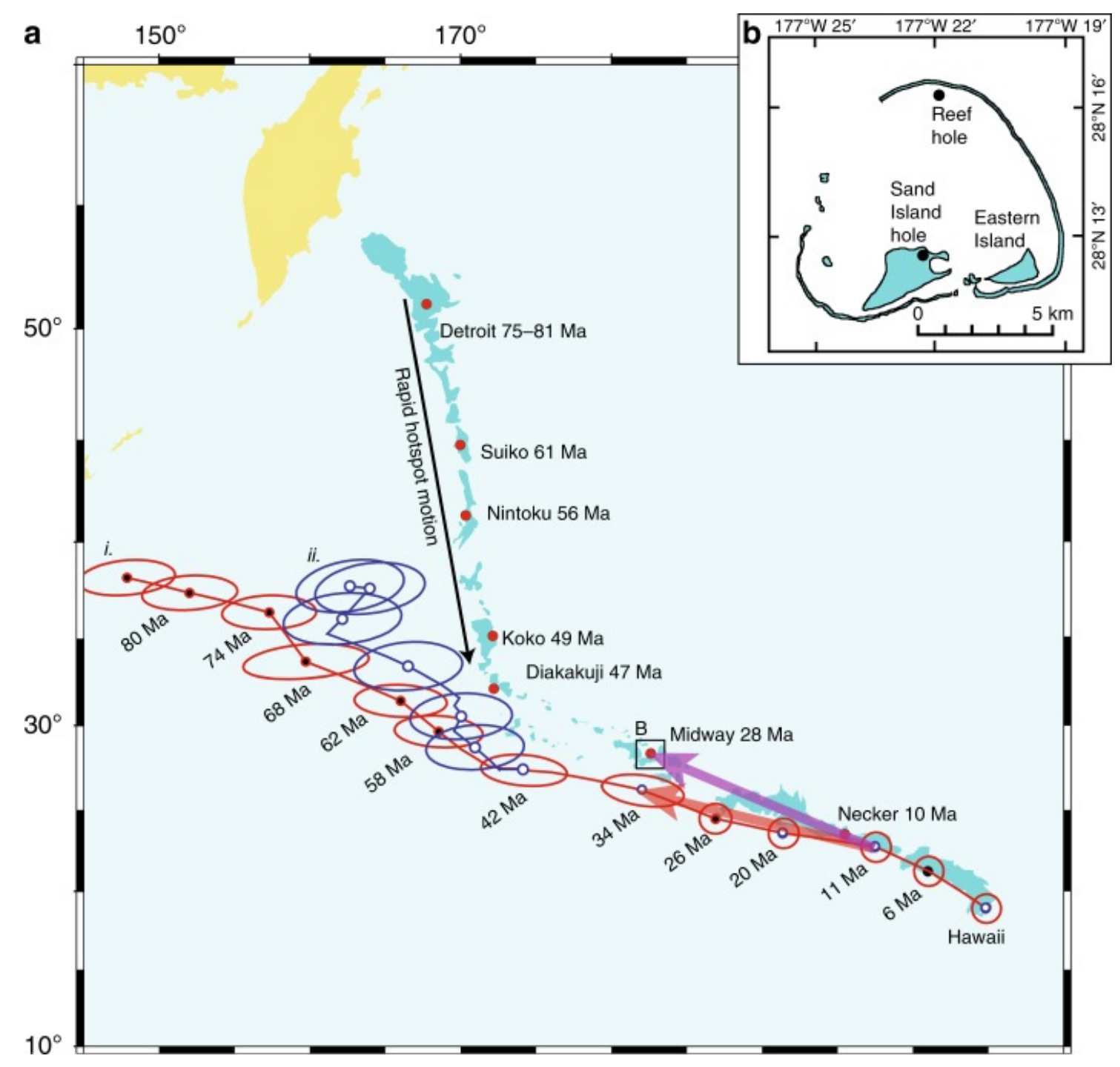

Figure 3. Location maps and plate-circuit predictions. A Hawaiian-Emperor island chain, with period of rapid southward movement highlighted. Predicted position of the Hawaiian hotspot using plate-circuit analyses; ( $i$ ) East-West Antarctica; (ii) Australia-Lord Howe Rise using updated Antarctica-Australia spreading history and rotations. B Midway Atoll with Reef and Sand Island drill sites highlighted. (sourced from Bono \& Tarduno, 2019)

\section{Plume Mantle Dynamism}

Large scale mantle flows may be disrupted during their ascent by magmatic currents or a mantle wind, a magnetically induced perturbation in magma flow during upwelling (Christensen, 1998). The middle portion of the mantle plume is less viscous than its advancing and solidifying front, and therefore, more susceptible to positional shifts influenced by the dynamo motion of magmatic fluid theorized to generate the Earth's magnetic field (Roberts \& Soward, 1992). Further, the lithospheric descent at convergent boundaries redirects the flow vector of the bordering asthenosphere downwards, fueling a convection cycle which forces mid-mantle layers to generally reverse direction e.g. Figure 2. 
This return flow convection current is hypothesized to move at speeds of up to five $\mathrm{cm} / \mathrm{year}$, antiparallel to lithospheric plate motion (Misuhiro, 1978).

The lithosphere plate motion near the center of tectonic plates forms an opposing flow vector in the upper asthenosphere, as the magma directly beneath the crust is displaced in a direction parallel to plate motion. This opposition in flow at varied depths creates continuous shearing as return flows horizontally displace the upwelling plume, partially attributing hotspot motion as a corollary to dominant plate activity. Horizontal heat transference (advection) of the plume, in compensation for the mid-mantle shear, results in diapiric instability and a large buoyancy flux as the front of the plume shifts away from the direction of plate motion. This reactionary motion could be inscribed in the curvatures of island arcs, where the maximum horizontal displacement may be equivalent this radius of curvature e.g. Figure 4 (Griffiths \& Richards, 1989).

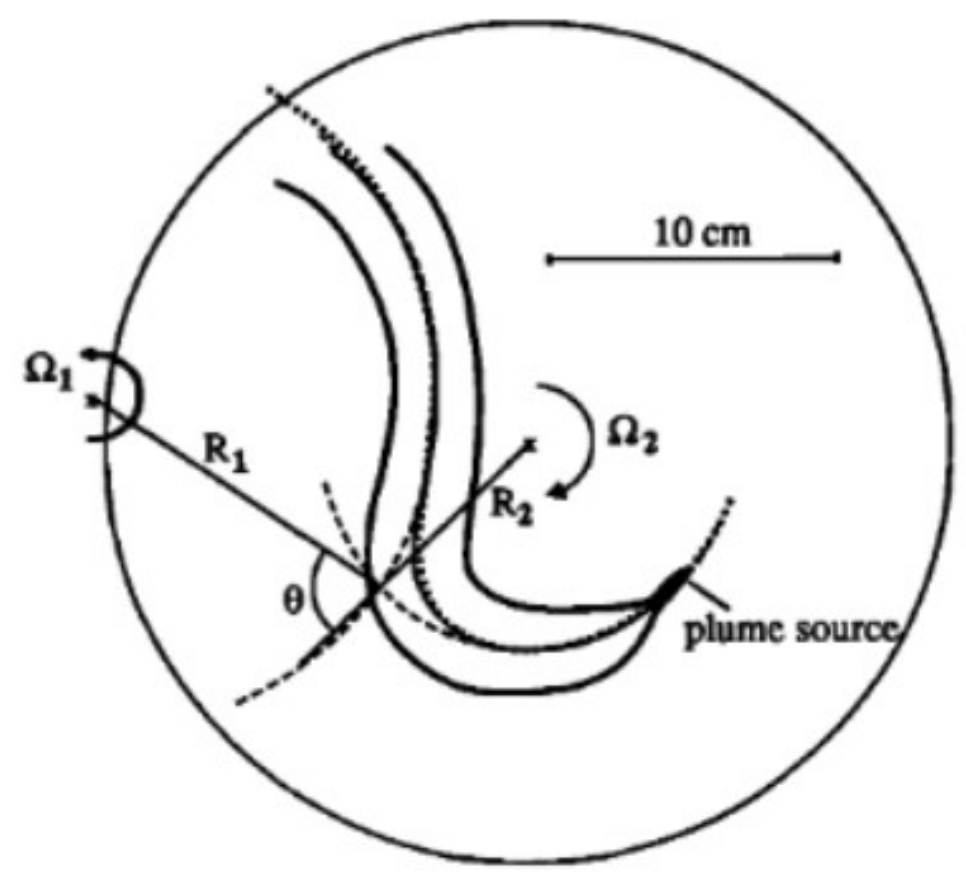

Figure 4. Results of experiment considering plume activity when subjected to a shift in rotation - simulation of the horizontal advection of plume upwellings due to mid-mantle return flow

Includes tracing of experimental plume track (solid), and circular arcs centered on the axes of rotation (broken curves). The theoretical flow (dotted line) very closely mirrors the experimental results, demonstrating that the horizontal displacement experienced by the plume is roughly equal to the radius of curvature expressed in the plume track. (sourced from Griffiths \& Richards, 1989)

Conversely, the intense pressure exerted by the diapir front could be driving the plate extension and actively increase volatility of plate motion at convergent boundaries, thereby strengthening these return flows and recursively driving the horizontal motions of the plume. 
Current estimates of Pacific plate motion predict a velocity of nearly $10 \mathrm{~cm}$ per year in a northwesterly direction, while the estimated velocity of the Hawaiian hotspot during its positional shift between 80 and 50 million years ago (Ma) is estimated anywhere between two to over four cm per year, drifting southernly (Tarduno, 2003). This significant motion of the hotspot cannot be discounted when attempting to decode the fundamental interaction of plume and tectonic plate activity.

It is far from settled as to whether mid-mantle flows displacing plume upwells are ubiquitous, an effect of global mantle wind, or if they are localized, principally formed by regional effects. If all hotspots are globally affected by a uniform displacement by such a mantle wind, they will remain relatively in the same position with respect to one another, remaining suitable for use as an external reference frame to judge plate motions. One study, however, points to a "coherent motion" of the Hawaiian hotspots positioning relative to African hotspots (Steinberger, 1998). Also, while the Hawaiian mantle plume has moved southwards by about 15 degrees latitude, as confirmed by argon age dating and palaeomagnetic data, the Louisville hotspot has remained within three to five degrees of its present latitude e.g. Figure 5. These results suggest that the Louisville and Hawaiian hotspots are moving independently, and not as a large-scale mantle wind in the Pacific (Koppers, 2012). This suggests that not only do hotspots residing under different lithospheric plates, such as the Hawaiian and African hotspots, move independently of one another, but also that hotspots beneath the same plate are not stationary with respect to each other either (Konrad \& Koppers, 2018). The variance in drift observed among these hotspots suggests regionally specific, mid-mantle flow properties may vary by a large magnitude and be sensitive to plate induced return flow as well as other local effects. 


\section{Macrothink}
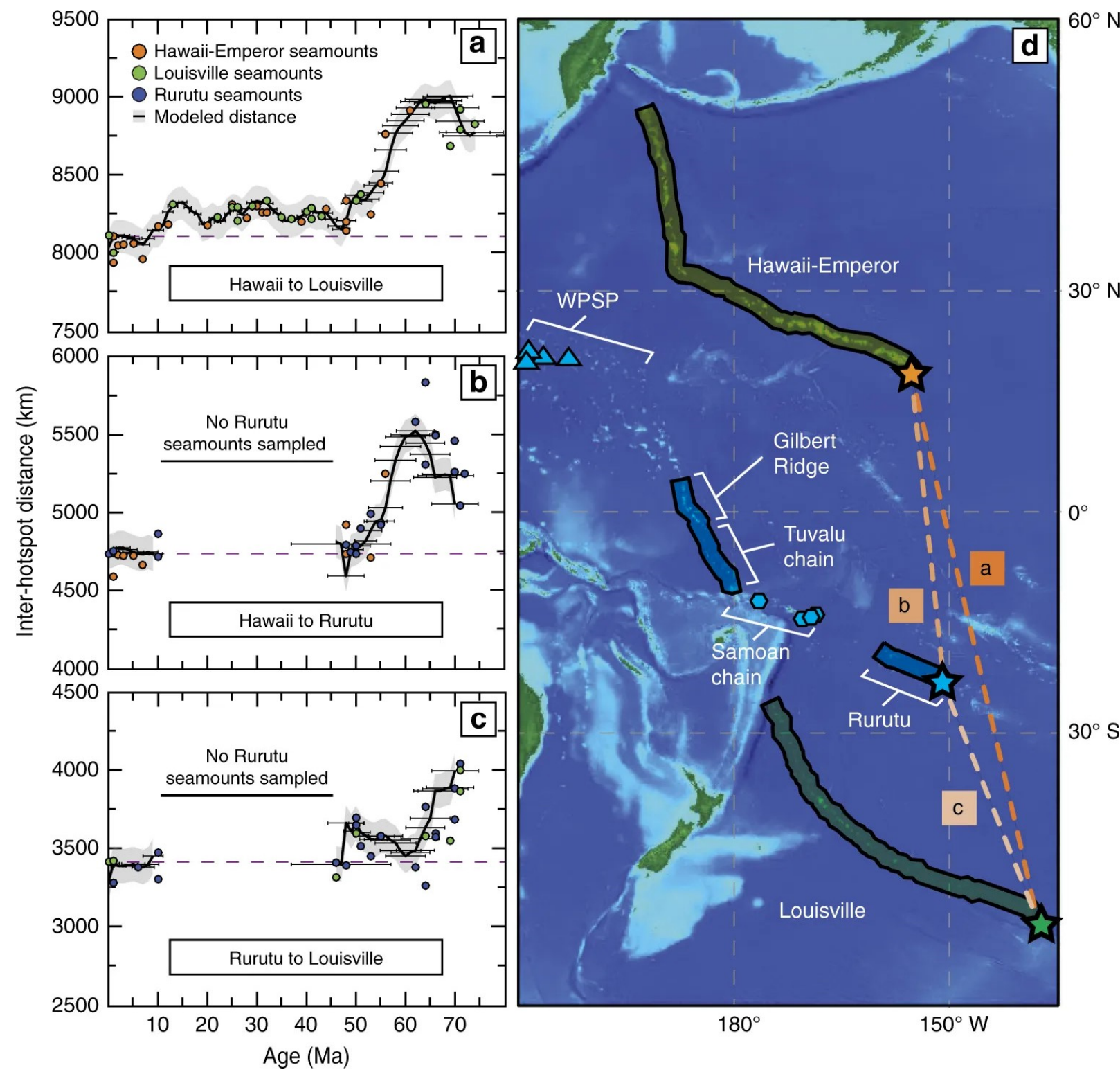

Figure 5. Inter-hotspot distances as a function of age and the geographic locations of the Hawaii and Louisville and Rurutu hotspots. a-c The black lines represent the distance between the two compared model hotspot chains. One sigma uncertainties are provided for reconstructed model ages at $1 \mathrm{Ma}$ increments and the gray shading represents distance uncertainties assuming a plume radius of $75 \mathrm{~km}$. a Hawaii compared to Louisville; $\mathbf{b}$ Hawaii compared to Rurutu; c Rurutu compared to Louisville. d A digital elevation map of the western Pacific showing the modeled reconstructions of the Hawaii-Emperor (orange), Rurutu (blue), and Louisville (green) chains. Stars denote the current hotspot locations presumed at Loihi Seamount, Arago Seamount, and the inferred Louisville hotspot location. Blue hexagons represent the location of seamounts with Rurutu-like geochemical compositions but lack age determinations. Blue triangles represent seamounts within the Western Pacific Seamount Province (WPSP) that contain ages consistent with belonging to the Rurutu chain. (sourced from Konrad \& Koppers, 2018) 


\subsection{Active or Passive Plumes}

The viewpoint advocating that mantle plumes are the primary drivers of tectonic activity (Plume Model) is ensconced within plate tectonic theory (Cronin \& Tasa, 2018). This theory defines the nature of mantle plumes as independent features, contributing toward plate motion. The locations of these plumes, and associated hot spots, are relatively constant. They only move slowly over long periods of time and generally are not responsive to near surface plate features. The deep earth forces driving the plumes are ultimately characterized by the chemistry and magmatic composition of the mantle. The plumes push their way through the lithospheric plate, serving to create and later recycle planetary crust.

In contrast to this active scenario, the Plate model describes mantle plumes as a reaction to dominant plate activity. The thinner and weaker central portions of tectonic plates form mantle plume diapirs as a passive reaction to lithospheric extension (Christensen, 1998). Under this model, the drifting motions observed in the Hawaiian hotspot are artifacts of plate motion and associated return flow characteristics (Christensen, 1998). While shallow mantle plumes may be more affected by plate motion due to extreme shear deformation, deep mantle plumes may be more stable. Paleomagnetic records of hotspots have confirmed they are not stationary over time, yet it is not certain whether this occurs passively due to plate mechanics (Plate model), or recursively driven by plume upwelling (Plume model).

\section{Balloons to the Rescue}

From a systems control perspective, a coupled nonlinear model that incorporates the properties of a viscously flowing mantle and buoyant lithospheric plates could perhaps provide an appropriate simulation for plume mantle flow. Cover two water balloons, one filled with air and one filled with a viscous fluid, with a semi-solid paste, paint, or putty. This coating simulates the lithospheric crust suspended above a fluid mantle. When laid on a flat surface, the edges of the balloon are compressed slowly, mirroring compression created by lithospheric plates at subduction zones. In this scenario, cracks and joints in this paste represent tectonic and plate features e.g. Figure 6. 


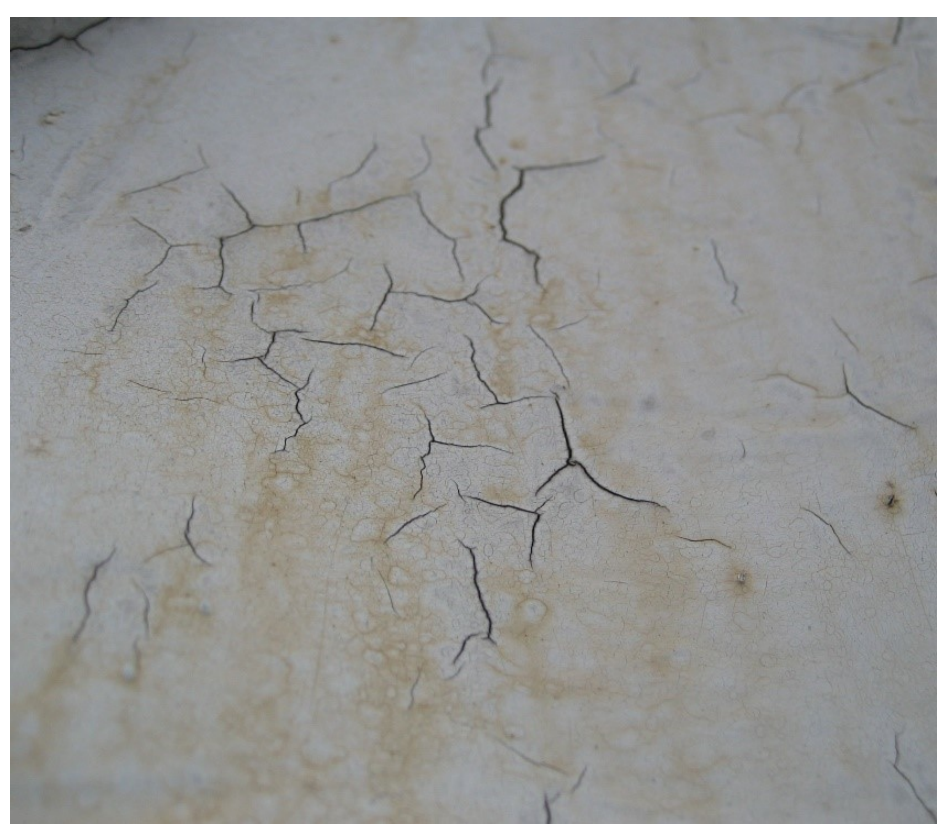

Figure 6. Cracks and creases in paint due to age and wear (slightly modified). Dynamic deformation of the underlying surface would exacerbate these features.

When this concept is extended to the balloon simulation, the viscosity of the interior fluid substance defines the deformative vibration, and subsequently the surface expression. (sourced from Wikipedia Commons: https://commons.wikimedia.org/wiki/File:Cracked_ Paint.JPG)

The viscous material inside the balloon results in a periodic response different to that of the air-filled balloon, likely caused by the disparate damping characteristics of their fluid interiors as well as respective interactions with the coating on the balloon's surface. The liquid-filled balloon will experience an underdamped vibration, while the other does not and settles almost immediately. Moreover, the extended periodic vibration in the liquid balloon will cause creasing and a greater disruption of the coating. This simple simulation illustrates that the material underlying a material or structure interacts with and informs the characteristics of structures which rest upon it. The complex, inhomogeneous, and viscous mantle must actively interact with the lithospheric motion of the plates. The motion of iron-rich magmatic rock in the lower mantle is theorized to generate the Earth's magnetic field, and in the Plume model, deep-mantle properties affect lithospheric traits directly and fundamentally influence the volatility of plume upwellings. Since plate motion reconstructions have failed to produce a viable model for the deformations observed in the Hawaiian-Emperor chain in isolation, the activity of the mantle, and specifically that of mantle plumes, must have an active component influencing the vector motion of the oceanic Pacific plate. The view is inclusive of the Plate model, which asserts that the chemical composition and characteristics of the upper mantle are primarily influenced by surface tectonic activity. 


\section{Discussion}

It is difficult to choose between either a Plume or Plate driven model of mantle rheology and its interaction with plate tectonics. Proponents of the Plume viewpoint may be merely fitting the model to the troves of recent data which tend to confirm the relative motion of hotspots with respect to each other. Plate model apostles could be finding it difficult to adapt to new experimental findings. This dispute has been cast within philosophical ideals where, according Imre Lakatos, a central or basic premise of a hypothesis is surrounded by a protective belt which adapts the central premise to accommodate new data and failed predictions (Foulger, 2019). The concerns are twofold: Is the Plume model composed of a degenerative protective belt, fitted to new data but unable to make new predictions, i.e., it is merely a descriptive theory? Or is the Plate hypothesis a foundational and progressive theory that will lend itself to testable predictions? The phrasing of this query is not entirely conducive to the elucidation of interrelated processes, which contribute towards the formation of geological features such as the Hawaiian-Emperor chain, a demonstratable record of both plume and plate driven dynamism.

This exclusionary approach is not a valid perspective. A coupled, multi-state and dynamically active system, such as that which exists at the boundaries of the fluid mantle, less-fluid composed asthenosphere, and solid lithospheric crust, is naturally codependent and mutually interactive. By considering both the Plume and Plate models together in such a system, componential contributions can be assigned to plate activity and plume dynamics. This integrative approach can explain hotspot tracks by combining global plate motions with intraplate deformation and movement of hotspot plumes through distortion by global mantle flow (Koppers, 2012). Although the notion of a uniform global mantle flow has been discounted by the discovery of coherent relative motions of hotspots with respect to one another in the same region, this combinative approach could still yield significant insight into the coevolution of these processes.

\section{Conclusion}

In future work, it may be possible to isolate a weighted significance of active mantle plume effects on the larger plate motion dynamics. Reconstructions of plate activity, in isolation, do not match up with features observed in historically significant formations such as the Hawaiian-Emperor chain (Koppers, 2012). In addition, several models of plume dynamics predict southward motion of the Hawaiian hotspot correlating with this disparity (Tarduno, 2003). An analytical approach could be designed to isolate components of motion corresponding to the active pressure-based influence of hotspots and the passive reaction of hotspots to plate tectonic processes. Such a numerical computational methodology may be the only way to isolate this relationship, as regional mid-mantle flows have a large influence on hotspot motion, and such a complex fluid system hidden beneath kilometers of lithospheric rock may not be possible to fully simulate. Rather, regional studies on previously well-established mantle and plate processes through the geometry of hotspot tracks could produce retroactive mapping on these complex mantle processes. Through this extensive 
historical, regional recreation, a more complete picture will emerge. Understanding these little-known mantle processes is the first step towards development of a cohesive systemic understanding of mantle and plate activity and the possible restructuring and synthesis of the dynamic processes of our planet.

\section{Acknowledgement}

The author graciously thanks Dr. Robert Blauvelt for his critical reading of the manuscript.

\section{References}

Bono, R. K., Tarduno, J. A., \& Bunge, H. P. (2019). Hotspot Motion caused the Hawaiian-Emperor Bend and LLSVPs are not fixed. Nature Communications, 10, 3370. https://doi.org/10.1038/s41467-019-11314-6

Christensen, U. (1998). Fixed hotspots gone with the wind. Nature News, 391, 847, 739-740. https://doi.org/10.1038/35736

Cronin, V. S., Tasa, D. S. (2018). Laboratory Manual in Physical Geology (11th ed.). San Francisco: Pearson Education, (37-39).

Foulger, G. R. (2019). Abstract: Do Mantle Plumes Exist? (Geological Society of America Annual Meeting in Phoenix, Arizona, USA - 2019). [Online] Available: https:/gsa.confex.com/gsa/2019AM/webprogram/Paper339327.html (February 10, 2020)

Griffiths, R. W., Campbell, I. H. (1990). Stirring and structure in mantle starting plumes. Earth and Planetary Science Letters, 99, 66-78. https://doi.org/10.1016/0012-821X(90) 90071-5

Griffiths, R. W., Richards, M. A. (1989). The Adjustment of Mantle Plumes to Changes in Plate Motion. AGU Journals, 16, 5, 437-440. https://doi.org/10.1029/GL016i005p00437

Konrad, K., Koppers, A. A. P., Steinberger, B., et al. (2018). On the relative motions of long-lived Pacific mantle plumes. Nature Communications, 9, 854. https://doi.org/10.1038/ s41467-018-03277-x

Koppers, A. A. P., Yamazaki, T., Geldmacher, J., Gee, J. S., et al. (2012). Limited latitudinal mantle plume motion for the Louisville hotspot. Nature Geoscience, 5, 911-917. https://doi.org/10.1038/ngeo1638

Mitsuhiro, T. (1978). Flow Under the Island Arc of Japan and Lateral Variation of Magma Chemistry of Island Arc Volcanoes. Journal of the Physics of the Earth, 26, S423-S435. https://doi.org/10.4294/jpe1952.26.Supplement_S423

Morgan, W. J. (1972). Deep Mantle Convection Plumes and Plate Motions. AAPG Bulletin, American Association of Petroleum Geologists, 56, 203-213. https://doi.org/10.1306/819 A3E50-16C5-11D7-8645000102C1865D 
Plate Tectonics. Pacific Northwest Seismic Network. [Online] Available: https://pnsn.org/outreach/about-earthquakes/plate-tectonics (February 10, 2020)

Roberts, P. H., Soward, A. M. (1992). Dynamo theory. Annual Reviews, 24, 459-512.

Steinberger, B., O'Connell, R. J. (1998). Advection of plumes in mantle flow: implications for hotspot motion, mantle viscosity and plume distribution. Geophysical Journal International, 132, 412-434. https://doi.org/10.1046/j.1365-246x.1998.00447.x

Tarduno, J. A., Duncan, R. A., Scholl, D. W., et al. (2003). The Emperor Seamounts: Southward Motion of the Hawaiian Hotspot Plume in Earth's Mantle. Science, 301, 5636, 1064-1069. https://doi.org/10.1126/science.1086442

Wilson, J. T. (1973). Mantle plumes and plate motions. Tectonophysics, 19, 2, 149-164. https://doi.org/10.1016/0040-1951(73)90037-1

\section{Copyrights}

Copyright for this article is retained by the author(s), with first publication rights granted to the journal.

This is an open-access article distributed under the terms and conditions of the Creative Commons Attribution license (http://creativecommons.org/licenses/by/4.0/) 